The book is also human in that it takes a liberal view of natural history, including definitions of fat-basket, harvest moon, World Wildlife Fund, pH, nature trail, conker. It gives slangy terms, and words only used in certain parts of the country, like Easter-Ledge (Lake District for bistort), Rail (Irish for caddis flies), Corbie (Scottish for raven), Heathpoult (Somerset for black grouse), Ouzel (Old English for blackbird). It is good to find that the definition of rabbit is enlarged with a short description of myxomatosis, that so many alternative names are given, that there is an index of species at the back of the book, and that 348 pages of fact can be bought for $8 \mathrm{~s}$. $6 \mathrm{~d}$. In short, I welcome and applaud this Fitter dictionary, and I hope its paperback format manages to survive the inevitably frequent investigations into its contents.

ANTHONY SMITH

Dawn, Dusk and Deer, by Arthur Cadman. Country Life, 30s.

Arthur Cadman has set himself the task of instructing the beginner in the art, science, intricacy and fascination of watching, studying and managing deer. He has salted his many lessons in venery with a number of homely, delightful and often amusing experiences.

Those who know the author personally will appreciate the forthright and often boyish enthusiasm that reveals his character in every line. For he is one of those nowadays rare people who live for as well as in the countryside, and for whom the changing faces of both animal and plant life, the variations of the weather, all add zest to his being.

Good wine tastes better out of beautiful glass and every book has added charm if attractively presented. Country Life and Mr. Tunnicliffe have played their part to ensure that this book shall appear to the best advantage. As always, Tunnicliffe has managed to portray the animals at their most graceful and appealing, and once again dumbfounds those who find animal pictures banal. His black and white drawings are lavishly spaced through the book and this alone makes it a must for one's library shelf. But such a book demands a second volume to satisfy the appetite it has produced.

DUDLEY FORWOOD

\title{
Birds in our Lives, edited by Alfred Stefferud: US Department of
} the Interior, $\$ 9.00$

The aim of this American book as stated by the editor is to widen public understanding of birds by giving a broad perspective of them as they affect and are affected by people, other birds and other forms of life and activities. He believes that this is the best way to achieve public support. His book should do just this. It is one of the most wide-ranging, popular symposiums on the subject of birds for the ordinary bird-watcher and bird lover in existence, imposing not only for its subject matter, which naturally chiefly concerns American birds, but also for the range of authors, beginning with a foreword by Stewart Udall, Secretary of the Department of the Interior, who emphasises that in this technological age there is necessity for us to learn about the inter-relationships of all living things.

All aspects of birds are treated, beginning with a look at the birds themselves and what they are, what they mean to us, their place in the arts, in recreation, as an economic problem, in nature, and finally their conservation and protection. Although each of the fifty-four chapters within the sections is comparatively short, the depth of treatment is impressive and often gives a comprehensive summary of the particular subject. Illustrations include 372 black and white photographs, mostly of very high standard, and 80 wash drawings by Bob Hines.

PETER CONDER 